Voss, E., Die Lebensbezüge von Fabel und Schwank im I6. Jh., Diss. (masch.) Rostock I945.

Schmidt, L., Melchior Khlesl in der zeitgenössischen Schwank-Anekdote, in: Jb. f. Landeskd. v. Niederösterreich, N. F. 30, 1949/52, S. $170-176$.

Sieber, F., Volksschwänke im Wandel der Zeit, in: Volkskunst 2, I953, H. 6, S. I 8 f.

Anthropophyteia. Jahrbücher f. Folkloristische Erhebungen u. Forschungen zur Entwicklungsgeschichte der geschlechtlichen Moral, hg. v. F. S. KRAuss, Io Bde und Beiwerk, I9II/I3.

\title{
VIII. DeR DRAMATISChE SChWANK
}

Die Bezeichnung Schwank wird in der Terminologie des Dramas erst im 19. Jh. üblich. Sie dient dazu, den Gegentypus zur ,Posse ${ }^{6}$ zu charakterisieren, die ein stark schematisierendes Handlungsschema zeigt, während der Schwank "alle komischen Elemente in eine spannungsreiche, in sich gerundete Handlung einordnet und „eine sehr domestizierte komische Person im Mittelpunkt" hat (Catholy, S. 222). Gegen Ende des 19. Jhs wird die Posse durch den Schwank verdrängt. Unsterbliche Figur des Schwanks ist etwa der Schauspieler Striese im »Raub der Sabinerinnen « der Brüder SchönthaN (I885). Erfolgreiche Schwänke wurden »Im weißen Rößl« von BLUMENTHAL und Kadelburg (I898), Ludwig Fulda's »Jugendfreunde « (1897) und »Die verlorene Tochter« (I9I5), Gustav von Moser's »Der Bibliothekar« (I878), »Veilchenfresser « (I876) und »Krieg und Frieden« ( 1879 ), gemeinsam mit FRANZ vON ScHÖNTHAN verfaßt, CARL LAUf's "Ein toller Einfall « (ז886), Ludwig Thoma's "Die Medaille« (I910), »Die Lokalbahn« (I902), »Erster Klasse« (I910), KURT KRAatz und Max Neal's $\gg$ Der Hochtourist (1903) und Walter Harlan's »Jahrmarkt zu Pulsnitz« (I904). Für die Forschung blieben diese Stücke weitgehend uninteressant; es findet sich kaum Literatur über sie. Auch an den Theatern, von einigen lokalen Volksbühnen abgesehen, werden Schwänke nur noch selten aufgeführt. Im Fernsehen hat diese leichte Unterhaltung jedoch eine neue Heimat gefunden.

\section{Literatur:}

Catholy, E., Posse, RL 3, ${ }^{2}$ I967, S. 220-223; Prang, H., Geschichte des Lustspiels, 1968; HoLL, K., Geschichte des dt. Lustspiels, I923, Nachdr. I964; Martin, E., Der Schwank, r92r. 